\section{Overview of attention deficit hyperactivity disorder in young children}

\author{
Ajay Singh, ${ }^{1}$ Chia Jung Yeh, 2 \\ Nidhi Verma, 3 Ajay Kumar Das 4 \\ 1Department of Early Childhood and \\ Elementary Education, College of \\ Education and Human Services, Murray \\ State University, Murray, KY, USA; \\ 2Human Development and Family \\ Science, College of Health and Human \\ Performance, East Carolina University, \\ Greenville, NC, USA; ${ }^{3}$ Department of \\ Psychology, Kurukshetra University, \\ Kurukshetra, India; ${ }^{4}$ Department of \\ Adolescent, Career and Special \\ Education, Murray State University, \\ Murray, KY, USA
}

\section{Abstract}

Attention deficit hyperactivity disorder (ADHD) is a complex disorder, which can be seen as a disorder of life time, developing in preschool years and manifesting symptoms (full and/or partial) throughout the adulthood; therefore, it is not surprising that there are no simple solutions. The aim of this paper is to provide a short and concise review which can be used to inform affected children and adults; family members of affected children and adults, and other medical, paramedical, non-medical, and educational professionals about the disorder. This paper has also tried to look into the process of how ADHD develops; what are the associated problems; and how many other children and adults are affected by such problems all over the world basically to understand ADHD more precisely in order to develop a better medical and or non-medical multimodal intervention plan. If preschool teachers and clinicians are aware of what the research tells us about ADHD, the varying theories of its cause, and which areas need further research, the knowledge will assist them in supporting the families of children with ADHD. By including information in this review about the connection between biological behavior, it is hoped that preschool teachers and clinicians at all levels will feel more confident about explaining to parents of ADHD children, and older ADHD children themselves about the probable causes of ADHD.

\section{Overview of attention deficit hyperactivity disorder in young children}

Literally thousands of studies have been conducted on attention deficit hyperactivity disorder (ADHD) and it's various predecessors in diagnostic nomenclatures prior to DSM-V (The Diagnostic and Statistical Manual of Mental Disorders-V). Despite this long research history, ADHD is not necessarily well understood among the lay public, given the many controversies and public misconceptions concerning the disorder.1,2 Longitudinal evidence suggests that childhood ADHD persists into young adulthood in $60-70 \%$ of the cases when defined relative to same-age peers and in $58 \%$ of the cases when DSM-V criteria and parental reports are used. ${ }^{3-6}$ These early studies of childhood hyperactivity excluded many children that would currently meet the DSM criteria for ADHD, particularly the inactive sub-type. ${ }^{7}$ The scientific status of ADHD is one of the most controversial issues in child health. $8-10$ This paper examines the overview of ADHD in children in relation to its genetics, taxonomy, neurobiology, comorbidity, diet, treatment, and concludes with a discussion.

\section{Précis of attention deficit hyperactivity disorder}

ADHD is recognized as a common childhood psychiatric disorder and has a strong genetic, neuro-biologic, and neurochemical basis. ${ }^{11,12}$ It is characterized by symptoms of inattention and/or impulsivity and hyperactivity which can significantly impact many aspects of behavior as well as performance, both at school and at home. ${ }^{13} \mathrm{ADHD}$ is characterized by pervasive and impairing symptoms of inattention, hyperactivity, and impulsivity according to DSM-V.1416 The World Health Organization (WHO) uses a different name hyperkinetic disorder (HD)but lists similar operational criteria for the disorder. ${ }^{17}$ Regardless of name used, ADHD is one of the most thoroughly researched disorders in medicine. 18 The DSM diagnostic criteria for ADHD were based on reviews of existing research and a field trial in which alternative diagnostic criteria were evaluated. 19

Classification of what constitutes ADHD has changed dramatically over the last 32 years, with each successive revision of the Diagnostic and Statistical Manual, the diagnostic criteria used to describe the disorder. Current classification for combined type ADHD requires a minimum of six out of nine symptoms of inattention of hyperactivity/impulsivity. $16,17,20$ In addition there must be some impairment from symptoms in two or more settings (e.g. home and school) and clear evidence of significant impairment in social, school or work functioning. The DSM also allows the classification of two sub-type disorders: i) predominantly inattentive where the child only meets criteria for inattention; and
Correspondence: Ajay Singh, Department of Early Childhood and Elementary Education, College of Education and Human Services, Murray State University 3103, Alexander Hall, Murray, KY 42071, USA

Tel.: + 1.270.809.3098

E-mail: ajaysingh363@gmail.com

Key words: Attention deficit hyperactivity disorder; preschool; children; families; intervention.

Contributions: AS, NV contributed equally as first authors.

Conflict of interest: the authors declare no potential conflict of interest.

Received for publication: 17 November 2014.

Revision received: 17 December 2014.

Accepted for publication: 18 Dcember 2014.

This work is licensed under a Creative Commons Attribution NonCommercial 3.0 License (CC BYNC 3.0).

(C) Copyright A. Singh et al., 2015

Licensee PAGEPress, Italy

Health Psychology Research 2015; 3:2115

doi:10.4081/hpr.2015.2115

ii) predominantly hyperactive-impulsive where only the hyperactive-impulsive criteria are met.

\section{Prevalence of attention deficit hyperactivity disorder}

The relatively prevalence of the disorder is high, affecting approximately $4 \%$ of all children, although estimates vary widely from $3 \%$ to $11 \%$ or more. ${ }^{21,22}$ The disorder usually begins in early childhood and is characterized by excessive activity, even when developmental level and limited behavioral control are taken into consideration. ${ }^{23,24}$ reviewed the findings of six large epidemiological studies that identified cases of ADHD within these samples. The prevalences found in these studies ranged from a low of $2 \%$ to a high of $6.3 \%$, with most falling within the range of $4.2 \%$ to $6.3 \%$. Other studies have found similar prevalence rates in elementary school-age children (4-5.5\%; in Breton et al.,25 7.9\% in BriggsGowan et al., ${ }^{26} 5-6 \%$ in DuPaul, ${ }^{27}$ and $2.5-4 \%$ in Pelham et al. ${ }^{28}$ Lower rates result from using complete DSM criteria and parent reports (2 $6 \%$ in Breton et al. ${ }^{25}$ and higher ones if just a cutoff on teacher ratings is used (up to $23 \%$ in DuPaul, $2715.8 \%$ in Nolan et al., ${ }^{29} 14.3 \%$ in Trites et al. ${ }^{30}$ Sex and age differences in prevalence are routinely found in research. For 
instance, prevalence rates may be $4 \%$ in girls and $8 \%$ in boys in the preschool age group, ${ }^{29}$ yet fall to $2-4 \%$ in girls and 6-9\% in boys during the 6- to 12-year-old age period based on parent reports..$^{25}$ The prevalence decreases again to $0.9-2 \%$ in girls and $1-5.6 \%$ in boys by adolescence. $25,31-33$ Overall ADHD affects $2 \%$ to $9 \%$ in school age children.

\section{Etiological elucidation of attention deficit hyperactivity disorder}

Underlying etiological explanations of ADHD can be simply divided into biological and environmental. In simple terms biological explanations include genetics, brain structure and their influence on neuropsychology, while predominant environmental explanations include problems during and after birth, exposure to environmental toxins, parenting and diet.

\section{Heredity of attention deficit hyper- activity disorder}

Heredity of ADHD has been an important issue. ${ }^{34}$ For years, researchers have noted the higher prevalence of psychopathology in the parents and other relatives of children with ADHD. Between $10 \%$ and $35 \%$ of the immediate family members of children with ADHD are also likely to have the disorder, with the risk to siblings being approximately $32 \% .35-37$

Even more striking is the finding that if a parent has ADHD, the risk to the offspring is 57\%.12 Thus, ADHD clusters significantly among the biological relatives of children with the disorder, strongly implying a hereditary basis to this condition. ${ }^{38}$ Subsequently, these elevated rates of disorders have been noted in African American samples with ADHD, ${ }^{39}$ as well as in girls with ADHD compared to boys. 40

\section{Genetic factor}

The heredity basis for psychiatric disorders was already recognized at the turn of the nineteenth century by Enail Kraepelin. 41 There is now little doubt that ADHD is a condition in which genetic factors (genetic differences between children) make a substantial contribution to the risk of the disorder.42 Genetic factors are accounted for $80 \%$ of the etiology of ADHD, while more recent studies have begun to examine which particular genes might be implicated in ADHD, ${ }^{43,44}$ reported an association between $\mathrm{ADHD}$ and a null allele of the $\mathrm{C} 4 \mathrm{~B}$ complement locus in the $M H C$-gene region of chromosome 6, a locus also associated with reading disability. 45 Interest in a potential genetic mechanism underlying ADHD increased with reports of an association with a single dopamine transporter gene, ${ }^{46}$ and with reports of variations within the D4 receptor gene. 47 Genetic studies have focused mainly on candidate genes involved in dopaminergic transmission. Several reasons exist for this particular focus, dopaminergic drugs (methylphenidate) are clinically efficacious in addressing the core problems associated with ADHD. A gene related to dopamine, the DRD4 (repeater gene), has been the most reliably found in samples of children with ADHD. 48 It is the seven-repeat form of this gene that has been found to be overrepresented in children with ADHD. 47 Such a finding is quite interesting, because this gene has previously been associated with the personality trait of high novelty-seeking behavior; because this variant of the gene affects pharmacological responsiveness; and because the gene's impact on postsynaptic sensitivity is primarily found in frontal and prefrontal cortical regions believed to be associated with executive functions and attention. ${ }^{49}$ The finding of an overrepresentation of the seven-repeat $D R D 4$ gene has now been replicated in a number of other studies, not only of children with ADHD, but also of adolescents and adults with the disorder. ${ }^{42,48}$

Monitoring the correspondence between the intended and actually executed action, a fundamental mechanism of behavioral regulation, is reflected by error-related negativity (ERN), an ERP component generated by the anterior cingulate cortex. Based on this process assumption, a study by LaHoste et al.50 examined genetic influences on the ERN and other components related to action monitoring (correct negativity, $\mathrm{CRN}$, and error positivity, $\mathrm{P}_{\mathrm{e}}$ ). A flanker task was administered to adolescent twins (age 12) including 99 monozygotic (MZ) and 175 dizygotic (DZ) pairs. Genetic analysis showed substantial heritability of all three ERP components (40-60\%) and significant genetic correlations between them. This study provides the first evidence for heritable individual differences in the neural substrates of action monitoring and suggests that ERN, CRN, and $\mathrm{P}_{\mathrm{e}}$ can potentially serve as endophenotypes for genetic studies of personality traits and psychopathology associated with abnormal regulation of behavior. 50

\section{Cognitive genetics}

The sequencing of the human genome and the identification of a vast array of DNA polymorphisms has afforded cognitive scientists with the opportunity to interrogate the genetic basis of cognition with renewed vigor. Advances in the understanding of the neural substrates of sustained and spatial attention arising from the cognitive neurosciences can help guide putative linkages in cognitive genetics. ${ }^{51}$ In line with catecholamine models of sustained attention, associations have been reported between sustained attention and allelic variation in the dopamine beta hydroxy- lase gene $(D B H)$, the dopamine D2 and D4 receptor genes (DRD2, DRD4) and the dopamine transporter gene (DAT1).51 Much evidence implicates the cholinergic system in spatial attention. Accordingly, individual differences in spatial attention have been associated with variation in an alpha- 4 cholinergic receptor gene (CHRNA4). APOE-4 allele dosage has been shown to influence the speed of attentional reorienting in independent samples of nonaffected individuals. Preliminary evidence in both healthy children and children with ADHD suggests association with variants of the DAT1 gene and the control of spatial attention across the hemifields. 51

\section{Fronto-striatal circuitry in attention deficit hyperactivity disorder}

Imaging studies using positron emission tomography (PET), and magnetic resonance imaging (MRI) techniques have implicated the fronto-striatal circuitry in ADHD, an area rich in dopaminergic activity. However certain meta-analytic studies have questioned the robust association between dopaminergic genes and ADHD.52 Other candidate genes have also been investigated including serotonin transporter genes. ${ }^{53}$ Genetic investigations aim to examine whether different genes contribute to specific aspects of ADHD. For example, a meta-analysis by Bellgrove and Mattingley has shown that the dopamine transporter gene DAT1 is more closely associated with the ADHD combined sub-type than with the inattentive +sub-type. 54 Future molecular genetic studies aim to examine gene-environment interactions, the extent to which environmental factors moderate genetic risks for ADHD. As well as gene-gene interactions, the extent to which having a cocktail of different genetic influences might elevate risk for ADHD.

\section{Brain structure}

A wealth of literature has examined the anatomical structure of the brain in children with ADHD. Using brain scanning technology such as MRI these studies suggest that the brain circuits linking the prefrontal cortex, striatum and cerebellum are not functioning normally in children with ADHD. 55 Further evidence has examined the relationship between brain structure and behavioral measures of inhibition and attention. These results suggest that compromised brain morphology of selected regions is related to behavioral measures of inhibition and attention. ${ }^{56}$ Another study suggests that abnormalities in circuits important for motor response selection contribute to deficits in response inhibition in children with ADHD.57 This lends support to the growing awareness of ADHD-associated anomalies in medial frontal regions which are important for the control of voluntary actions. Studies using 
PET to assess cerebral glucose metabolism have found diminished metabolism in adults with ADHD, particularly in the frontal region. ${ }^{58,59}$ Using a radioactive tracer that indicates dopamine activity, 60 found abnormal dopamine activity in the right midbrain region of children with ADHD, and discovered that severity of symptoms was correlated with the degree of this abnormality. Another study pointed that children with ADHD were found to have a smaller corpus callosum, particularly in the area of the genu and splenium and that region just anterior to the splenium. ${ }^{61}$ Interestingly, the study by Zametkin et al. ${ }^{62}$ also found smaller cerebellar volume in those with ADHD. This would be consistent with views that the cerebellum plays a major role in executive functioning and the motor presetting aspects of sensory perception that derive from planning and other executive actions. ${ }^{63}$ MRI showed no differences between groups in the regions of the corpus callosum in either of the other studies. ${ }^{62,64}$ Further investigations of anatomical structure may allow the development of pharmacological interventions for ADHD, 65 which are better targeted to specific sites of action in the brain.

\section{Neurobiology of attention deficit hyperactivity disorder}

Neurobiology of ADHD has been another valued topic of investigation. 66 Researchers describe at least 11 different neuroanatomical theories of ADHD. ${ }^{67}$ These theories can be categorized into two domains. The bottom-up theories propose disturbances in subcortical regions, such as the thalamus, and hypothalamus and reticular activating systems are responsible for ADHD symptomology. The topdown theories attribute the dysfunction to frontal and prefrontal and sagittal cortices. Smaller frontal lobe or right prefrontal cortex was found for the ADHD groups in all studies that examined this measure. Five of six studies found a smaller anterior or posterior corpus callosum. Four of six found loss of the normal caudate asymmetry, and these four also found a smaller left or right globus pallidus. ${ }^{6}$ Neuroimaging studies of children with ADHD have investigated and found evidence of abnormalities in the frontal cortex, basal ganglia, corpus callosum, and cerebellum. ${ }^{69-72}$ The cerebellum is functionally linked with the prefrontal cortex, and three anatomical measures, namely the right globus pallidus volume, caudate asymmetry, and left cerebellum volume, correlate highly with ADHD in children.68 Preliminary evidence has not found differences in the thalamus in children with ADHD. 62,73

\section{Role of the basal ganglia}

The role of the basal ganglia in ADHD has been given serious importance in neuropsychological research. The basal ganglia are a collection of large subcortical structures that can be divided into two sets of core structures: i) the striatum consisting of the caudate, putamen, and ventral striatum and ii) the pallidum or globus pallidus consisting of the external segment, internal segment, and ventral pallidum. The striatum receives input from the entire cerebral cortex, thalamus, substantia nigra, and amygdala and sends projections to the pallidum and substantia nigra. The pallidum sends input to the thalamic nuclei and additional subcortical nuclei, where information will be sent back to the frontal or prefrontal cortex. ${ }^{74}$ The organization of the striatum is important in the execution of motor planning, sequencing, and coordination, as well as feedback and learning after motor execution, ${ }^{75}$ suggest that the striatum serves as a crossroads, combining sensory-motor information with emotional processing from the amygdala and dopamine mediated reinforcement. The primary neurotransmitter involved in modulation of the basal ganglia is dopamine, and disruption of this system has been found in ADHD. Initial studies found higher levels of the dopamine metabolite, and homovanillic acid in cerebral spinal fluid were positively correlated with the amount of hyperactivity in boys. ${ }^{62}$ A recent genetic study found that alleles of the gene encoding dopamine beta hydroxylase, an enzyme that breaks down dopamine, may be related to the expression of ADHD.76 Further support for dopamine dysfunction in ADHD comes from a functional MRI study that found children with ADHD had reduced activity in the frontal-striatal regions and impaired performance on response inhibition tasks. ${ }^{77}$ Additionally, methylphenidate, which acts on the dopamine transporter (DAT), increased both frontal-striatal activity and performance on response inhibition tasks. A study using single PET-CT found that adults with ADHD had increased levels of striatal DAT compared to normal controls, which may lead to decreased availability of striatal dopamine in ADHD. 78

Research on the role of the basal ganglia in ADHD has primarily focused on the caudate. ${ }^{79}$ The caudate has been implicated in a complex loop, receiving information from the association cortices and indirectly sending it via the thalamus to the prefrontal cortex..$^{80}$ Studies have found neuroanatomical differences in the caudate of children with ADHD with mixed results. 56,62,69,81-83 Found that boys with ADHD had a smaller right caudate; recently, this finding was not replicated in ADHD girls. ${ }^{69}$ In boys with $\mathrm{ADHD}$, smaller right caudate volumes were found to significantly correlate with poor accuracy on sensory selection tasks, and left and right caudate volumes were negatively correlated with mean reaction times. ${ }^{81}$ Conflicting results found ADHD adolescents had larger right caudate than normal adolescents, and the right caudate volume was associated with poorer performance on attention tasks and higher ratings of hyperactivity and impulsivity. 83 Another study found that children with ADHD had smaller left caudate volumes. ${ }^{73,82}$ More recently, Manor et al. ${ }^{56}$ reported that boys with ADHD were found to have a decreased volume of the left head of the caudate. These children were also more likely to show a reversed caudate asymmetry when compared to healthy controls, with the left being smaller than right. Moreover, a significant relationship between the reduction in left caudate volume and performance on behavioral inhibition tasks was found. In addition, children displaying reversed caudate asymmetry $(\mathrm{L}<\mathrm{R})$ were more likely to perform poorly on tasks of behavioral inhibition and attention regardless of group membership. ${ }^{56,81}$ It has been also previously found that reversed caudate asymmetry was related to deficits in response execution tasks in ADHD. This evidence suggests that asymmetry of the caudate regardless of volume has important implications in attention and behavioral control. Finally, functional imaging studies have found decreases in blood flow to the caudate in ADHD. ${ }^{62,84}$

\section{Role of the putamen}

The role of the putamen has also been studied as an etiological factor for the ADHD. 85 The putamen is hypothesized to be part of the motor loop because it receives information from the sensory-motor cortex and then sends it indirectly back to the premotor regions of the frontal cortex. Based on the putamen's anatomical connections and function, a role for the putamen in ADHD is possible although currently unclear because of equivocal evidence. ${ }^{80}$ There are relatively few studies investigating the neuroanatomical role of the putamen in ADHD. ${ }^{69}$ Another study have not found volumetric differences in the putamen between children with ADHD and healthy controls. ${ }^{62}$ In addition, they found that the volume of the putamen did not correlate with performance on response inhibition tasks. However, two studies suggest that the putamen may actually be important in the expression of ADHD symptomology. Researchers found that the ADHD diagnosis was significantly associated with the titer of two ant streptococcal antibodies. 86

In addition, they found that higher antibodies titers were associated with larger volumes in the left putamen and right globus pallidus in children with ADHD.86 Although this study found structural evidence for the role of the putamen in ADHD, the second study demon- 
strates functional differences in the putamen of children with ADHD. Recent advances in functional MRI technology have provided new methods to investigate blood flow to various regions of the brain. Functional MRI relaxometry allows researchers to investigate the resting or steady state conditions and medicationrelated changes and were able to indirectly assess blood volume to the striatum (caudate and putamen). ${ }^{75}$ They found that blood flow to both sides of the putamen was decreased in ADHD children compared to normal children. In addition, they found that blood flow to the left was more decreased than blood flow to the right side. They found no differences in blood flow to the thalamus and caudate, although there was a non-significant trend in the right caudate. Methylphenidate administration significantly altered the blood flow to the right and left putamen, and changes were correlated to the child's unmedicated state.

There were no significant differences in blood flow to the caudate off or on medication. Filipek et al.75 found strong associations between measures of activity and inattention with T2-RT measures in the putamen. They propose that ADHD symptoms are closely related to functional abnormalities in the putamen, which is closely involved in the control of motor behavior. These hypotheses lay the foundation for our study of the neuroanatomy of the putamen in children with ADHD. Investigators in their study using magnetic resonance imaging scans of boys in residential treatment with symptoms of ADHD and psychopathic traits found no differences in the total, left and right putamen volumes across the ADHD or control group. A significant reversal of asymmetry across groups was found; children with ADHD more frequently had a smaller left putamen than right. In contrast, the control group more frequently has a smaller right than left putamen.

Several studies have examined cerebral blood flow using single-photon emission computed tomography (SPECT) in children with ADHD and normal children. 68,72 They have consistently shown decreased blood flow to the prefrontal regions (most recently in the right frontal area), and to pathways connecting these regions with the limbic system via the striatum and specifically its anterior region known as the caudate, and with the cerebellum. 87,88

\section{Neuropsychology of attention deficit hyperactivity disorder}

Studies examining the neuropsychology of ADHD provide an opportunity to understand the relationship between underlying biological processes and symptoms of ADHD. For many years it was accepted that symptoms of ADHD were the result of cognitive dysregulation. ${ }^{89}$ The behavior of a child with ADHD resulted from insufficient forethought, planning and control. ${ }^{90}$ Evidence to support this view point came from many studies using neuropsychological tests which demonstrated that children with ADHD performed less well on these tests than did matched controls to match familiar figures, children with ADHD demonstrated more impulsive responding and higher error rates than did matched controls. 91,92

\section{Cognitive dysregulation}

A summary of ADHD as a disorder of cognitive dysregulation suggested that the relationship between biology and behavior in children with ADHD was mediated by inhibitory dysfunction. ${ }^{93}$ In contrast to the dominant view, researchers offered an alternative view of ADHD, not as a disorder of cognitive dysregulation, but as a motivational style. This viewed ADHD as a functional response by the child, aimed at avoiding delay. This alternative viewpoint of ADHD was based on other studies, ${ }^{92}$ which showed that most of the neuropsychological evidence to support ADHD as a result of cognitive dysregulation was confounded by delay. To demonstrate this, researchers got children with ADHD and match control children to participate in the matching familiar figures test, and found the same results as previous studies. ${ }^{92}$ Children with ADHD made more impulsive responses and more errors. However, researchers pointed out that all these studies involved trial constraints where as soon as one trial ended the next began and were confounded with delay. ${ }^{92}$ In order words, children with ADHD made more impulsive responses because it allowed them to complete the task quicker and therefore escape delay. When researchers re-ran their study under time constraint (for a fixed period of time where early or impulsive responses had no influence on delay), children with ADHD performed no differently from controls. ${ }^{92}$ Results of these studies lead to the development of the delay aversion hypothesis, ${ }^{94}$ which characterized the influence of delay on behavior dependent upon whether the child has control over their environment or not. When the child is in control of their environment they can choose to minimize delay by acting impulsively, e.g. by skipping the queue at the end of the slide! When the child is not in control of their environment, or at least where they are expected to behave in certain ways or face sanctions, the child would choose to distract themselves from the passing of time. For example, in a classroom context during literacy lessons the child could achieve this either by daydreaming (inattention) or by fidgeting (hyperactivity). A summary of ADHD as a motivational style suggests that the relationship between biology and behavior in ADHD is mediated by delay aversion.

Traditionally these two different accounts of ADHD have both sought to independently explain the disorder. However, a study by Sonuga-Barke et al. ${ }^{95}$ compared the measurement of both of these hypotheses in a head-tohead study. Results of this study showed that measures used to test each hypothesis were uncorrelated, demonstrating that they measured different constructs. Both sets of measures were correlated with ADHD, and when combined were highly diagnostic, correctly distinguishing 87.5 of cases from non-cases. These results suggested that both accounts appeared to help to explain ADHD, but that neither explanation was the single theory of $A D H D$ which both theoretical camps had been searching for. Based on these findings, researchers proposed his dual pathway model of ADHD.93 This model proposed two possible routes between biology and ADHD behavior. The first one is through cognitive dysregulation and another via motivational style. Clinically the dual pathway model suggests that there may be merit in targeting different sub-types with specific treatments, as well as allowing the development of novel interventions, perhaps aimed at desensitizing delay. Some have suggested ways in which the greater understanding about the influence of delay aversion on the development of ADHD could be used to develop alternative interventions. ${ }^{93,96}$ These suggestions include the use of delay fading, a technique to systematically reorganize the child's delay experience, as a means of increasing tolerance for delay, and reducing ADHD symptoms.

\section{Prenatal}

Some studies have not found a greater incidence of prenatal (pregnancy or birth complications) in children with ADHD compared to normal children whereas others have found a slightly higher prevalence of unusually short or long labor, fetal distress, low forceps delivery, and toxemia or eclampsia in children with ADHD. ${ }^{97}$ Nevertheless, though children with ADHD may not experience greater pregnancy complications, prematurity, or lower birthweight as a group, children born prematurely or who have markedly lower birth-weights are at high risk for later hyperactivity or ADHD.

Researchers found that smoking and maternal stress during the pregnancy is associated with onset of ADHD during early childhood. Similarly observed that parental smoking during pregnancy predicts non-responsiveness to intervention targeting ADHD symptoms in elementary school children. Hartsough et al. observed that behavioral symptoms of ADHD were predicted by a lower ponderal index $\left(\mathrm{kg} / \mathrm{m}^{3}\right),{ }^{98}$ a smaller head circumference, and a smaller head-circumference-to-length ratio. 
Length of gestation, mother's age, tobacco and alcohol during pregnancy and pre-pregnancy, body mass index or parity, the monthly gross income of family, child's BMI at the age of five or six years or gender didn't have any significant effect on the behavioral symptoms of $\mathrm{ADHD}$ at the age of five or six.

\section{Exposure to environmental toxins}

Exposure to environmental toxins specifically lead has also been reviewed as a causal factor for ADHD. An amazing variety of toxins extent in the modern environment have deleterious effects on the central nervous system that range from severe organic destruction to subtle brain dysfunction. ${ }^{99,100}$ Toxic metals are ubiquitous in the modern environment, as are organohalide pesticides, herbicides, and fumigants, and a wide range of aromatic and aliphatic solvents. ${ }^{101}$ All these categories of environmental pollutants have been linked to abnormalities in behavior, perception, cognition, and motor ability that can be subtle during early childhood but disabling over the long term.102 Children exposed acutely or chronically to lead, arsenic, aluminum, mercury, or cadmium are often left with permanent neurological sequelae that include attentional deficits, emotional lability, and behavioral reactivity. 101 Elevated body lead burden has been shown to have a small but consistent and statistically significant relationship to the symptoms of ADHD. ${ }^{103,104}$ However, even at relatively high levels of lead, fewer than $38 \%$ of children in one study were rated as having the behavior of hyperactivity on a teacher rating scale,104 implying that most lead-poisoned children do not develop symptoms of ADHD. And most children with ADHD likewise, do not have significantly elevated lead burdens. 105

\section{Environmental influences}

Environmental influences on ADHD have also been reviewed extensively. Attention deficit hyperactivity disorder is best viewed as a gene $\times$ environment interaction. ${ }^{106}$ Children who have a genetic predisposition will express the disorder when put in the correct environment, typically one characterized by chaotic parenting. ${ }^{107}$ The best evidence for environmental influences on ADHD come from intervention studies which have demonstrated improvements in ADHD symptoms, when parents have been taught alternative parenting skills. ${ }^{108,109}$ Results of these studies do not necessarily imply that parents of children with ADHD are bad parents. In fact, influence of parenting on ADHD is best viewed from an interactionist viewpoint. The relationship between ADHD and parenting may result from both negative aspects of the child influencing the parents' behavior, and negative aspects of the parents influencing the child's behavior. Studies examining mother-child interaction have found that children with ADHD are less often on task, less compliant, less responsive and more active than controls; researchers investigated both mother-son and father-son interactions and found that parents of boys with ADHD were more demanding, aversive and power assertive; $110-112$ while the findings of Buhrmester et al. ${ }^{113}$ have demonstrated that mothers of children with ADHD have been found to be more negative, controlling, intrusive and disapproving, and less rewarding and responsive than mothers of children without ADHD.

Research finds that ADHD affects the interactions of children with their parents, and hence the manner in which parents may respond to these children. ${ }^{114}$ Those with ADHD are more talkative, negative and defiant; less compliant and cooperative; more demanding of assistance from others; and less able to play and work independently of their mothers.115-118 Their mothers are less responsive to the questions of their children, more negative and directive, and less rewarding of their children's behavior. ${ }^{107,116}$ Mothers of children with ADHD have been shown to give both more commands and more rewards to sons with ADHD than to daughters with the disorder, ${ }^{119,120}$ but also to be more emotional and acrimonious in their interactions with sons. ${ }^{112}$ Children and teens with ADHD seem to be nearly as problematic for their fathers as their mothers. ${ }^{112,118,121}$ Contrary to what may be seen in normal mother-child interactions, the conflicts between children and teens with ADHD (especially boys) and their mothers may actually increase when fathers join the interactions. ${ }^{112,121}$ So while parents of children with ADHD may engage in less than optimal parenting, it is easy to see how such responses might have evolved.

In addition, genetic studies highlight the familial basis of ADHD.122,123 Children with ADHD are more likely to have a parent with ADHD. ADHD symptoms in parents usually interfere with consistent and appropriate parenting. Researchers found that ADHD in parents prevented effective parental monitoring and consistent use of constructive parenting techniques.124 Other researchers found that parental ADHD symptoms were associated with lax discipline, ${ }^{125}$ while Harvey et al. ${ }^{126}$ found that high ADHD symptoms in mothers were a barrier to successful psychosocial intervention for pre-school children with ADHD.

\section{Medication}

Most widely researched and commonly prescribed treatments for ADHD are the psychostimulants, including methylphenidate, amphetamine, and pemoline. ${ }^{2,127}$ Several studies have demonstrated the short-term efficacy of stimulant compared to placebo conditions in improving both core ADHD symptoms and important ancillary features of the disorder. 128 Controlled studies of stimulants have shown their effect on reducing interrupting in class, reducing task-irrelevant activity in school, improving performance on spelling and arithmetic tasks, improving sustained attention during play, and improving parent-child interaction.

Meaningful effects have been documented across a wide array of outcome domains, cognitive attentional performance, school behavior, and learning, parent-child interactions, interaction with peers, and with a wide variety of assessment approaches, direct observations of behavior in natural and laboratory settings, and objective laboratory performance. 129

\section{Diet}

Diet is another environmental influence, often cited by parents as having an adverse influence on the ADHD symptoms of their child. 130 Specifically, food additives, refined sugars and fatty acid deficiencies have all been associated with ADHD symptoms. ${ }^{131}$

However, the majority of this literature comes from older studies, with a variety of methodological problems, and small sample sizes. ${ }^{131}$ In fact, a large recent randomized control trial examined the influence of food colorings and benzoate preservatives on pre-school hyperactivity. Results demonstrated a general adverse effect of food coloring and benzoate preservatives on hyperactive behavior of preschool children, based on parental reports, but not on simple clinic assessment. Children with high levels of hyperactivity were no more vulnerable to this effect than children with low levels of hyperactivity. 132 While improving children's diet might impact on their general health and improve their overall behavior, the clinical importance of dietary change as a means of remediating ADHD remains doubtful. 133

\section{Co-morbidity}

ADHD appears to be associated with a wide variety of other psychiatry problems, which are often co-morbid with it. ADHD co-occurs with other childhood disorders far more often than it appears alone.134 Notable associations exist with Oppositional Defiant Disorder (ODD), Conduct Disorder (CD), tic disorder, mood disorder, autism spectrum disorder, specific learning disorder such as dyslexia, ${ }^{135,136}$ depression and anxiety. About $50-60 \%$ of children with ADHD meet criteria for ODD, even 
in the pre-school period. 137 Busch and colleagues (2002) reported that ADHD children in primary care settings were significantly more likely than non-ADHD clinic controls to demonstrate mood disorders (57\%) such as depression, multiple anxiety disorders (31\%), and substance use disorders (11.5\%). However, in the recent British Child Mental Health Survey, ${ }^{138}$ anxiety was not associated with ADHD when adjustment was made for the presence of a third disorder. It is widely accepted that ADHD is a co-morbid disorder. Copeland et al. ${ }^{135}$ point out that co-morbidity can mean a common underlying etiology which leads to two or more different disorders, or that one disorder leads to another, or even that two unrelated disorders co-occur. The term co-morbid also implies that their entities are morbid conditions, i.e. diseases. High rates of comorbidity with either other neurodevelopmental disorders (e.g., mental retardation, and learning disabilities) or psychiatric disorders (e.g., anxiety) make delineation of the phenotype difficult. 139

Some studies found that $47 \%$ children with ADHD have co-morbid ODD, 140-142 27\% have anxiety disorder and 7\% have mood disorder. $38 \%$ of children with ADHD were found to have CD and $13 \%$ have depression. In fact, the vast majority of co-morbidities with ADHD represent functional impairments and symptoms, which are not rooted in specific diseases. ${ }^{135}$ Studies of clinic-referred children with ADHD find that between $54 \%$ and $67 \%$ will meet criteria for a diagnosis of ODD by 7 years of age or later. ODD is a frequent precursor to $\mathrm{CD}, \mathrm{a}$ more severe and often (though not always) later occurring stage of ODD. ${ }^{143}$. The co-occurrence of $\mathrm{CD}$ with $\mathrm{ADHD}$ may be $20-50 \%$ in children and 44-50\% in adolescence with ADHD. ${ }^{144}$ By adulthood, up to $26 \%$ may continue to have $\mathrm{CD}$, while $12-21 \%$ will qualify for a diagnosis of antisocial personality disorder (ASPD).

In addition to associations with other psychiatric disorders children with ADHD are also more likely than their non-ADHD counterparts to experience a substantial array of developmental, social and health risks. It therefore seems important to discuss associated problems along with co-morbidity.

\section{Motor coordination}

Children with ADHD often demonstrate poor motor co-ordination or motor performance and balance. ${ }^{145-147}$ Substantial evidences have been observed for problems in motor development and motor execution children with ADHD. ${ }^{148}$ Clinical and epidemiological studies report that $30 \%$ to $50 \%$ of children with ADHD suffer from motor coordination problems. ${ }^{146}$ These percentage are dependent of the type of motor assessment, referral sources and the cut-off points used.149-151 As noted by Needleman et al., 105 children with ADHD display greater dif- ficulties with the development of motor coordination, planning and execution of complex, lengthy tasks, and novel chains of goal directed responses.

\section{Academic functioning}

Children with ADHD have an impaired academic functioning and are usually at an educational disadvantage upon school entry.152,153 ADHD children are more likely than their nonADHD peers to demonstrate difficulties with basic mathematics and pre-reading skills during their first year at school.147,154,155 Executive academic functions were found to be core deficits specific to ADHD. Girls with ADHD were found to be less impaired than boys with ADHD. ${ }^{156}$ Even pre-school children with ADHD demonstrate educational disadvantage, DuPaul et al. ${ }^{157}$ demonstrated that their sample of pre-school ADHD children demonstrated deficits in pre-academic skills even prior to formal school entry. The pre-school ADHD children in their sample scored on average one standard deviation lower on the Battelle Developmental Index, ${ }^{158}$ than did their nonADHD control group. Researchers emphasized the importance of look away behavior (inattention) as a major reason for poor academic achievement. ${ }^{159}$

Clinic-referred children with ADHD often present with lower scores on intelligence tests than control groups, specifically verbal intelligence with differences ranging from 7 to 10 standard score points. ${ }^{160}$ Studies with community samples of ADHD children have also demonstrated negative associations between ADHD and intelligence. ${ }^{161,162}$

Children with ADHD demonstrate serious difficulties with psychosocial functioning. Social adjustment is often given little attention on assessment protocols, given its designation as an associated feature of ADHD. ${ }^{15}$ However, the high levels of disruptive behavior demonstrated by ADHD children increases the likelihood of negative reactions from parent, teachers and also peers. ${ }^{163}$ In addition, negative social interactions with peers ultimately lead to peer's rejection, 164 because these social difficulties are often resistant to psychosocial and pharmacological treatment, 165 they are expected to continue into adolescence, and even adulthood when criteria for the disorder may no longer be met. 166 The patterns of disruptive, intrusive, excessive, negative, and emotional social interactions that have been found between children with ADHD and their parents, have also been found to occur in the children's interactions with teachers and peers. ${ }^{157,167,168}$ It should come as no surprise, then, that those with ADHD receive more correction, punishment, censure, and criticism than other children from their teachers, as well as more school suspensions and expulsions, particularly if they have ODD/CD.168,169
In their social relationships, children with ADHD are less liked by other children, have fewer friends, and are overwhelmingly rejected as a consequence, ${ }^{170}$ particularly if they have comorbid conduct problems.107,125,171,172 Another research study demonstrated that the co-occurrence of conduct disorder and anxiety disorder with ADHD in childhood predicted a more severe course for ADHD in adolescence. ${ }^{173}$

\section{Unintentional physical injury}

Children with ADHD appear to be at a greater risk for unintentional physical injury and accidental poisoning. 157,174 In one of the first studies of the issue, Stewart and colleagues found that four times as many hyperactive children as control children (43\% vs. $11 \%)$ were described by parents as accidentprone. Later studies have also identified such risks; up to $57 \%$ of children with hyperactivity or ADHD are said to be accident-prone by parents, relative to $11 \%$ or fewer of control children. ${ }^{175,176}$ Most studies find that children with ADHD experience more injuries of various sorts than control children. In one study, $16 \%$ of the hyperactive sample had at least four or more serious accidental injuries (broken bones, lacerations, head injuries, severe bruises, lost teeth, etc.), compared to just $5 \%$ of control children.2,177 found that $68 \%$ of children with DSM-IV-TR ADD, compared to $39 \%$ of control children, had experienced physical trauma sufficient to warrant sutures, hospitalization, or extensive/painful procedures. Several other studies likewise found a greater frequency of accidental injuries than among control children. Researchers found that children with ADHD were at a greater risk for suffering fractures, ${ }^{178}$ most likely as a result of hyperactive and impulsive behavior. Children with AD/HD are also more likely than their non-ADHD counterparts to be injured as pedestrians, to inflict injuries to themselves, to sustain injuries to multiple body regions and to experience head injury. ${ }^{179}$ Knowledge about safety does not appear to be lower in these children; implying interventions aimed at increasing knowledge about safety may have little impact. 180

\section{Sleep disturbances}

Studies report an association between ADHD and sleep disturbances found that sleep problems occurred twice as often in ADHD as in control children.181-184 The problems are mainly more behavioral and include settling difficulties, a longer time to fall asleep, and instability of sleep duration, tiredness at awakening or frequent night waking. The direction of effect, between ADHD and sleep problems is unclear. It is possible that sleep difficulties increase ADHD symptoms during the daytime, as the research on normal children implies. ${ }^{105}$ Yet some research finds that the sleep prob- 
lems of children with ADHD are not associated with the severity of their symptoms; this suggests that the disorder, not the impaired sleeping, is what contributes to impaired daytime alertness, inattention, and behavioral problems. 184,185

While knowledge about the associations between ADHD and other related variables is useful in terms of diagnostic profiles, less is known about the impact of related variables on the long-term outcome for the disorder. Even less is known about the specificity of these associated problems to ADHD. In the preschool years a wealth of evidence now exists comparing the symptoms of pre-school ADHD symptoms to its school-aged counterpart. Children with a pre-school variant of ADHD present with the same symptom structure, ${ }^{186,187}$ similar associated impairment and developmental risk, 187 and similar patterns of neuropsychology. 188 Despite the similarities between pre-school ADHD and school-aged ADHD, little is known about what constitutes impairment during the pre-school years although school readiness should be what clinicians focus on. And even less is known about the relationship between early hyperactivity and later expression of the ADHD disorder. ${ }^{189}$

While originally conceived of as a disorder of childhood and adolescence, evidence suggests scientific merit and clinical value in examining ADHD in adulthood, ${ }^{40,189}$ as well as the pre-school period.189 ADHD symptoms have been shown to persist into later life with up to $40 \%$ of childhood cases continuing to meet full criteria in the adult years. ${ }^{190,191}$ Adult ADHD appears to share many characteristics of the childhood disorder. Similar to their childhood counterparts, adults with ADHD display impairment in the interpersonal, vocational and cognitive domains. ${ }^{192-194}$ The adult and childhood disorders also appear to share a common neuropathology, 195,196 and demonstrate a similar response to treatment. 197

\section{Conclusions}

We have discussed two different possible causes of ADHD in neurological research. The top down theory says that ADHD begins with frontal and pre-frontal lobe dysfunction. The other theory says that the sub-cortical regions, the thalamus and the hypothalamus are responsible for ADHD. Neuro-imaging doesn't show abnormality in the thalamus, but does show changes in the frontal and prefrontal area. Researchers agree that genetic factors are a strong contribution to the occurrence of ADHD.

DSM-IV has an aura of scientific legitimacy, many authors have written about its shortcomings in terms of reliability and validity. 198,199
The primary function and goal of the DSM,200 is to lend credibility to the claim that certain (mis) behaviors are mental disorders and that such disorders are medical diseases. Although the DSM-IV is often used when discussing mental illnesses, be it in a research setting or a clinical practice setting. Researchers apply points out that such extensive use does not in itself guarantee either its validity or reliability. ${ }^{201}$ The DSM-IV is purely descriptive and presents no new scientific insights about the causes of the many mental disorders it lists. Despite a wide level of acceptance, ADHD is not an uncontested condition.202 For example, another researcher has argued that ....the working dogma that ADHD is a disease or neurobehavioral condition does not at this time hold up. ${ }^{203,204}$ A more recent perspective presented by Lollar has also stated that there are no valid neurological markers for the diagnosis of ADHD. ${ }^{205}$ Additionally, Shaw et al. ${ }^{206}$ observe that there is currently no verifiable objective evidence to support the claims of ADHD advocates. Given the lack of validity as a medical condition, it is important to ask why the label of ADHD is applied, and under what conditions?

Another researcher found no association between DAT1 and ADHD. ${ }^{207}$ Another gene for which there have been many studies is the dopamine receptor D4, DRD4, on chromosome 11. Another researchers found no evidence of an association between ADHD and DRD4.208 Environmental effects could also include childspecific experiences of salient environmental influences such as maternal lifestyle or parenting. ${ }^{209}$ Childhood ADHD symptoms do remit across time for some,, 4210 but not all children. ${ }^{209}$

Some of the controversial treatments have involved dietary management, herbs and antioxidants. The removal of artificial food colorings and preservatives from the diet is an indispensable and practicable clinical intervention in ADHD, but rarely is sufficient to eliminate symptomatology. ${ }^{102}$ Up to 88 percent of ADHD children react to these substances in sublingual challenge testing, but in blinded studies no child reacted to these alone. Allergies to the foods themselves must also be identified and eliminated.211 Sugar intake makes a marked contribution to hyperactive, aggressive, and destructive behavior.212,213-222 Overall body of evidence currently does not support dietary use as sole therapy for ADHD. There is a group of children with ADHD who do not respond well to treatment. More resources should be made available to help them, through clinical research and clinical-based treatment. ${ }^{214}$

The actual degree to which genetic heritability may predispose to childhood onset of ADHD is still an open question. ${ }^{102}$ Population studies indicate attentional problems, conduct problems, and emotional problems tend to cluster within families. ${ }^{215,223,224}$ Genetics and environment are notoriously difficult to separate within the family unit, and researchers suggested the genetic predisposition to ADHD might fuel a negative family atmosphere that exacerbates latent ADHD in the child, 102,225,226

It is unknown whether the association of motor coordination problems with ADHD is comparable across ages. The limitation in daily life caused by poor motor performance varies with age. 146 Four to six years old children mainly have problems with dressing, use of scissors, drawing, trying shoelaces, and riding a bike. Children seven to ten years old encounter difficulties in writing, dressing, swimming, constructional play, ball skills and outdoor play, while eleven to nineteen year olds have problems of clumsiness in writing, drawing, ball skills, poor table manners and tool use. ${ }^{218}$

Research on long term effects and safety of ADHD medications has been especially lacking. ${ }^{36,219}$ According to researchers of a study of psychotropic drugs used with preschoolers, earlier ages of initiation and longer duration of treatment means that the possibility of adverse effects on the developing brain cannot be ruled out. Another research study of longer term ADHD treatments suggested the side effects such as depression, worrying, and irritability from ADHD medications. 227,228 In some of these children, drug therapy is insufficient because of persistent symptoms of coexisting conditions. 228,229 Future studies will be needed to define the subgroups clearly. There is much to learn about it.

\section{References}

1. Ghanizadeh A. Psychometric analysis of the new ADHD DSM-V derived symptoms. BMC Psychiatry 2012;12:21.

2. Jenson P. Current concept and controversies in the diagnosis and treatment of attention deficit hyperactivity disorder. Curr Psychiatry Rep 2000;2:102-9.

3. Burke JD, Rowe R, Boylan K. Functional outcomes of child and adolescent oppositional defiant disorder symptoms in young adult men. J Child Psychol Psychiatry 2014;55:264-72.

4. Barkley RA, Fisher M, Smallish L, Fletcher $K$. The persistence of attention deficit/hyperactivity disorder into young adulthood as a function of reporting source and definition of disorder. $\mathrm{J}$ Abnorm Psychol 2002;111:279-89.

5. Keenan K, Shaw DS, Walsh B. DSM-III-R disorders in preschool children from lowincome families. J Am Acad Child Adolesc Psychiatry 1997;36:620-7. 
6. Lavigne JV, Gibbons RD, Chirstoffel KK. Prevalence rates and correlates of psychiatric disorders among preschool children. J Am Acad Child Adolesc Psychiatry Med 1996;35:204-14.

7. McGough JJ, Barkley RA. Diagnostic controversies in adult attention deficit hyperactivity disorder. Am J Psychiatry 2004;161:1948-56.

8. Currie J, Kahn R. Children with disabilities: introducing the issue. Future Children 2012;22:3-11.

9. Breggin P. Talking back to ritalin: what doctors aren't telling you about stimulants and ADHD. $2^{\text {nd }}$ ed. Cambridge: De Capo Press; 2001.

10. Stein, D. Unraveling the ADD/ADHD fiasco: successful parenting without drugs. Kansas City: Andrews McMeel; 2001.

11. National Institute of Clinical Excellence (NICE). Attention deficit hyperactivity disorder Diagnosis and Management of ADHD in children, young people and adults. London: NICE Clinical Guideline; 2009.

12. Biederman J, Faraone SV, Mick E, et al. High risk for attention deficit hyperactivity disorder among children of parents with childhood onset of the disorder: a pilot study. Am J Psychiatry 1995;152;4315.

13. Faraone SV, Sergeant J, Gillberg C, Biederman J. The worldwide prevalence of ADHD: is it an american condition? World Psychiatry 2003;2:104-13.

14. Epstein JN, Loren RE. Changes in the definition of ADHD in DSM-5: subtle but important. Neuropsychiatry 2013;3:455-8.

15. American Psychiatric Association. Diagnostic and statistical manual of mental disorders. $4^{\text {th }}$ ed. Washington, DC: American Psychiatric Pub.; 1994.

16. American Psychiatric Association. Diagnostic and statistical manual of mental disorders, DSM-IV-TR. $4^{\text {th }}$ ed. Washington, DC: American Psychiatric Pub.; 2000.

17. Kessler RC, Üstün TB. The world mental health (WMH) survey initiative version of the world health organization (WHO) composite international diagnostic interview (CIDI). Int J Methods Psychiatr Res 2004;13:93-121.

18. Goldman LS, Genel M, Bezman PJ, Slanetz PJ. Diagnosis and treatment of treatment of attention deficit/hyperactivity disorder in children and adolescents: council on scientific affairs. JAMA 1998;279:1100-07.

19. McBurnett K. Attention deficit/hyperactivity disorder. In: Frances A, Widiger T, Pincus $\mathrm{H}$, et al, eds. DSM-IV source book. Vol. 3, Washington, DC: American Psychiatric Press; 1997. pp 111-143.
20. Depue BE, Burgess GC, Willcutt EG, et al. Inhibitory control of memory retrieval and motor processing associated with the right lateral prefrontal cortex: evidence from deficits in individuals with ADHD. Neuropsychologia 2010;48:3909-17.

21. Sheppard B, Chavira D, Azzam A, et al. ADHD prevalence and association with hoarding behaviors in childhood onset OCD. Depression Anxiety 2010;27:667-74.

22. Zametkin AJ, Ernst M. Current concept problems in the management of attention deficit hyperactivity disorder. $\mathrm{N}$ Engl $\mathrm{J}$ Med 1999;340:1.

23. Elia J, Ambrosini PJ, Rapoport JL. Treatment of attention deficit disorder. $\mathrm{N}$ Engl J Med 1999;340:780-8.

24. Szatmari, P. The epidemiology of attention-deficit hyperactivity disorders. Child Adolesc Psychiatr Clin N Am 1992;1;36172.

25. Breton J, Bergeron L, Valla JP, et al. Quebec children mental health survey: prevalence of DSM-III-R mental health disorders. J Child Psychol Psychiatry 1999;40:375-84

26. Briggs-Gowan MJ, Horwitz SM., SchwabStone ME, et al. Mental health in pediatric settings: distribution of disorders and factors related to service use. J Am Acad Child Adolesc Psychiatry 2000;39:841-9.

27. DuPaul GJ. Parent and teacher ratings of ADHD symptoms: psychometric properties in a community based sample. J Clin Child Psychol 1991;20:245-53.

28. Pelham WE, Gnagy EM, Greenslade KE, Milich R. Teacher ratings of DSM-III-R symptoms for the disruptive behavior disorders. J Am Acad Child Adolesc Psychiatry 1992;31:210-8.

29. Nolan EE, Gadow KD, Sprafkin J. Teacher reports of DSM-IV ADHD, ODD, and CD symptoms in schoolchildren. $\mathrm{J}$ Am Acad Child Adolesc Psychiatry 2001;40:241-9.

30. Trites RL, Dugas F, Lynch G, Ferguson B. Incidence of hyperactivity. J Pediatr Psychol 1979;4,179-88.

31. Lewinsohn PM, Hops H, Roberts RE, et al. Adolescent psychopathology: I. Prevalence and incidence of depression and other DSM-III-R disorders in high school students. J Abnorm Psychol 1993;102:133-44.

32. McGee R, Feehan M, Williams S, et al. DSM-III disorders in a large sample of adolescents. J Am Acad Child Adolesc Psychiatry 1990;29:611-9.

33. Romano E, Tremblay RE, Vitaro F, et al. Prevalence of psychiatric diagnoses and the role of perceived impairment: findings from an adolescent community sample. J Child Psychol Psychiatry 2001;42:451-62.

34. Szatmari, P. The epidemiology of atten- tion-deficit hyperactivity disorders. Child Adolesc Psychiatr Clin N Am 1992;1:36172 .

35. Biederman J, Faraone SV. Attentiondeficit hyperactivity disorder. Lancet $2005 ; 366: 237-48$.

36. Null G, Feldman M. The benefits of going beyond conventional therapies for ADHD. J Orthomol Med 2005;20:75-88.

37. Biederman J, Newcorn J, Sprich S. Comorbidity of attention defect hyperactivity disorder with conduct, depressive, anxiety, and other disorders. Am J Psychiatry 1991;148:564-77.

38. Biederman J, Faraone SV, Keenan K, Tsuang MT. Evidence of a familial association between attention deficit disorder and major affective disorders. Arch Gen Psychiatry 1991;48:633-42.

39. Pauls DL. Genetic factors in the expression of attention-deficit hyperactivity disorder. J Child Adolesc Psychopharmacol 1991;1:353-60.

40. Welner Z, Welner A, Stewart M, et al. A controlled study of siblings of hyperactive children. J Nerv Ment Dis 1977;165:110-7.

41. Martin N, McDougall M, Hay DA. What are the key directions in the genetics of attention deficit hyperactivity disorder? Curr Opin Psychiatry 2008;21:356-61.

42. Samuel VJ, George P, Thornell A, et al. A pilot controlled family study of DSM-III-R and DSM-IV ADHD in African-American children. J Am Acad Child Adolesc Psychiatry 1999;38:34-9.

43. Faraone SV, Biederman J, Mick E, et al. Family study of girls with attention deficit hyperactivity disorder. Am J Psychiatry 2000;157:1077-83.

44. Burmeister M, Mclnnis MG, Zollner S. Psychiatric genetics: progress amid controversy. Nature Rev Genet 2008;9:527-40.

45. Stevenson J, Asherson P, Hay D, et al. Characterising the ADHD phenotype for genetic studies. Develop Sci 2005;8:11521.

46. Todd RD. Genetics of childhood disorders: XXI. ADHD, part 5: a behavioral genetics perspective. J Am Acad Child Adolesc Psychiatry 2000;39:1571-4.

47. Warren RP, Singh VK, Averett RE, et al. Immunogenetic studies in autism \& related disorders. Mol Chem Neuropathol 1996;28:77-81.

48. Cardon LR, Smith SD, Fulker DW, et al. quantitative traits locus for reading disability on chromosome 6. Science 1994;266:276-9.

49. Cook EH, Stein MA, Krasowski MD, et al. Association of attention-deficit disorder and the dopamine transporter gene. Am J Hum Genet 1995;56:993-8.

50. LaHoste GJ, Swanson J, Wigal SB, et al. Dopamine D4 receptor gene polymor- 
phism is associated with attention deficit hyperactivity disorder. Mol Psychiatry 1996;1:121-4.

51. Faraone SV, Biederman J, Weiffenbach B, et al. Dopamine D4 gene 7-repeat allele and attention deficit hyperactivity disorder. Am J Psychiatry 1999;156:768-70.

52. Qian Q, Wang Y, Zhou R, et al. Family based and case control association studies of DRD4 and DAT1 polymorphisms in Chinese attention deficit hyperactivity disorder patients suggest long repeats contribute to genetic risk for the disorder. Am J Med Genet Part B: Neuropsychiatr Genet 2004;128:84-9.

53. Anokhin AP, Golosheykin S, Heath AC. Heritability of frontal brain function related to action monitoring. Psychophysiology 2008;45:524-34.

54. Bellgrove MA, Mattingley JB. Molecular genetics of attention. Ann N Y Acad Sci 2008;1129:200-12.

55. Purper-Ouakil D, Wohl M, Mouren MC, et al. Meta-analysis of family-based association studies between the dopamine transporter gene and attention deficit hyperactivity disorder. Psychiatr Genet 2005;15:53-9.

56. Manor I, Eisenberg J, Tyano S, et al. Family-based association study of the serotonin transporter promoter region polymorphism (5-HTTLPR) in attention deficit hyperactivity disorder. Am J Med Genet 2001;105:91-5.

57. Waldman ID, Faraone SV. A meta-analysis of linkage and association between the dopamine transporter gene (DAT1) and childhood ADHD. Behav Genet 2002;32:487.

58. Castellanos FX, Acosta MT. Syndrome of attention deficit with hyperactivity as the expression of an organic functional disorder. Revista Neurologia 2002;35:1-11.

59. Semrud-Clikeman M, Steingard RJ, Filipek P, et al. Using MRI to examine brain-behavior relationships in males with attention deficit disorder with hyperactivity. J Am Acad Child Adolesc Psychiatry 2000;39:477-84.

60. Suskauer SJ, Simmonds DJ, Fotedar S, et al. Functional magnetic resonance imaging evidence for abnormalities in response selection in attention deficit hyperactivity disorder: Differences in activation associated with response inhibition but not habitual motor response. J Cogn Neurosci 2008;20:478-93.

61. Schweitzer JB, Faber TL, Grafton ST, et al. Alterations in the functional anatomy of working memory in adult attention deficit hyperactivity disorder. Am J Psychiatry 2000;157:278-80.

62. Zametkin AJ, Nordahl TE, Gross M, et al. Cerebral glucose metabolism in adults with hyperactivity of childhood onset. $\mathrm{N}$ Engl J Med 1990;323:1361-6.

63. Hynd GW, Semrud-Clikeman M, Lorys AR, et al. Corpus callosum morphology in attention deficit-hyperactivity disorder: morphometric analysis of MRI. J Learn Disabil 1991;24:141-6.

64. Castellanos FX, Giedd JN, Hamburger SD, et al. Quantitative brain magnetic resonance imaging in attention-deficit/hyperactivity disorder. Arch Gen Psychiatry 1996;53:607-16.

65. Diamond A. Close interrelation of motor development and cognitive development and of the cerebellum and prefrontal cortex. Child Dev 2000;71:44-56.

66. Cao YL, Cui QT, Tang CH, Chang X. [Association of CLOCK gene T3111C polymorphism with attention deficit hyperactivity disorder and related sleep disturbances in children]. Zhongguo Dang Dai Er Ke Za Zhi 2012;4:285. [Article in Chinese]

67. Peadon E, Thomas D, Elliott EJ. Pharmacological interventions for ADHD symptoms in children with fetal alcohol spectrum disorders (FASD).The Cochrane Library. 2012.

68. Tripp G, Wickens JR. Neurobiology of ADHD. Neuropharmacology 2009;57:57989.

69. Bledsoe JC, Semrud-Clikeman M, Pliszka SR. Neuroanatomical and neuropsychological correlates of the cerebellum in children with attention-deficit/hyperactivity disorder-combined type. J Am Acad Child Adolesc Psychiatry 2011;5:593-601.

70. Tannock R. Attention deficit hyperactivity disorder: advances in cognitive, neurobiological, and genetic research. J Child Psychol Psychiatry 1998;39;65-99.

71. Castellanos FX, Giedd JN, Berquin PC, et al. Quantitative brain magnetic resonance imaging in girls with attentiondeficit hyperactivity disorder. Arch Gen Psychiatry 2001;5:289-98.

72. Lindenberg A, Brinkmeyer J, Dahmen N, et al. The German multi centre study on smoking related behaviour-description of a population based case control study. Addict Biol 2011;16:638-53.

73. Barkley RA. Attention-deficit hyperactivity disorder: a handbook for diagnosis and treatment. 2nd ed. New York: Guilford Press; 1998. pp 44-52.

74. Hendren RL, De Backer I, Pandina GJ. Review of neuroimaging studies of child and adolescent psychiatric disorders from the past 10 years. J Am Acad Child Adolesc Psychiatry 2000;39:815-28.

75. Filipek PA, Semrud-Clikeman M, Steingard RJ, et al. Volumetric MRI analysis comparing subjects having attentiondeficit hyperactivity disorder with normal controls. Neurology 1997;48:589-601.

76. Wellington TM, Semrud-Clikeman M, Gregory AL, et al. Magnetic resonance imaging volumetric analysis of the putamen in children with ADHD combined type versus control. J Atten Disord 2006;10:171-80.

77. Teicher MH, Anderson CM, Glod CA, et al. Functional deficits in basal ganglia of children with attention-deficit/hyperactivity disorder show with functional magnetic resonance imaging relaxomety. Nat Med 2000;6:470-4.

78. Navia BA, Smith KM, Kleyner Y, et al. Gentic analysis of the D4DR, DAT1 and $\mathrm{D}$ [Beta]H genes in sib pairs with ADHD. Am J Hum Genet 2000;67:340.

79. Vaidya CJ, Austin G, Kirkorian G, et al. Selective effects of methylphenidate in attention deficit hyperactivity disorder: a functional magnetic resonance study. Proc Natl Acad Sci 1998;95:14494-9.

80. Krause KH, Dresel SH, Krause J, et al. Increased striatal dopamine transporter in adult patients with attention deficit hyperactivity disorder: effects of methylphenidate as measured by single photon emission computed tomography. Neurosci Lett 2000;285:107-10.

81. Sobel LJ, Bansal R, Maia TV, et al. Basal ganglia surface morphology and the effects of stimulant medications in youth with attention deficit hyperactivity disorder. Am J Psychiatry 2010;167:977-86.

82. Wellington TM, Semrud-Clikeman M, Gregory AL, et al. Magnetic resonance imaging volumetric analysis of the putamen in children with ADHD combined type versus control. J Atten Disord 2006;10:171-80.

83. Casey BJ, Castellanos FX, Giedd JN, et al. Implication of right frontostriatal circuitry in response inhibition and attentiondeficit/hyperactivity disorder. J Am Acad Child Adolesc Psychiatry 1997;6:374-83.

84. Hynd GW, Hern KL, Novey ES, et al. Attention deficit-hyperactivity disorder and asymmetry of the caudate nucleus. J Child Neurol 1993;8:339-47.

85. Mataro M. Magnetic resonance imaging measurements of the caudate nucleus in adolescents with attention-deficit hyperactivity disorder and its relationship with neuropsychological and behavioral measures. Arch Neurol 1997;54:963-8.

86. Peterson BS. Neuroimaging in child and adolescent neuropsychiatry disorder. J Am Acad Child Adolesc Psychiatry 1995;34:1560-77.

87. Peterson BS, Leckman JF, Tucker D, et al. Preliminary findings of antistreptococcal antibody titers and basal ganglia volumes in tic, obsessive-compulsive, and attention-deficit/hyperactivity disorders. Arch 
Gen Psychiatry 2000;57:364-72.

88. Gustafsson P, Thernlund G, Ryding E, et al. Associations between cerebral bloodflow measured by single photon emission computed tomorgraphy (SPECT), electroencephalogram (EEG), behavior symptoms, cognition and neurological soft signs in children with attention-deficit hyperactivity disorder (ADHD). Acta Paediatrica 2000;89:830-5.

89. Sieg KG, Gaffney GR, Preston DF, Hellings JA. SPECT brain imaging abnormalities in attention deficit hyperactivity disorder. Clin Nucl Med 1995;20:55-60.

90. Nigg JT. Is ADHD a disinhibitory disorder? Psychol Bull 2001;127:571-9.

91. Schachar R, Mota VL, Logan GD, et al. Confirmation of an inhibitory control deficit in attention-deficit/hyperactivity disorder. J Abnorm Child Psychol 2000;28:227-35.

92. Inoue K, Nadaoka T, Oiji A, et al. Clinical evaluation of attention-deficit hyperactivity disorder by objective quantitative measures. Child Psychiatry Hum Dev 1998;28:179-88.

93. Sonuga-Barke EJB. Psychological heterogeneity in AD/HD - a dual pathway model of behaviour and cognition. Behav Brain Res 2002;130:29-36.

94. Sonuga-Barke EJS, Houlberg K, Hall M. When is impulsiveness not impulsive. The case of hyperactive children's cognitive style. J Child Psychol Psychiatry 1994;35:1247- 53.

95. Sonuga-Barke EJS, Williams E, Hall M, Saxton T. Hyperactivity and delay aversion III: the effect on cognitive style of imposing delay after errors. J Child Psychol Psychiatry 1996;37:189-94.

96. Solanto MV, Abikoff H, Sonuga-Barke E, et al. The ecological validity of delay aversion and response inhibition as measures of impulsivity in AD/HD: a supplement to the NIMH multimodal treatment study of AD/HD. J Abnorm Child Psychol 2001;29:215-8.

97. Sonuga-Barke EJS. On the reorganization of incentive structure to promote delay tolerance: a therapeutic possibility or ADHD. Neural Plasticity 2004;11:23-8.

98. Hartsough CS, Lambert NM. Medical factors in hyperactive and normal children: prenatal, developmental, and health history findings. Am J Orthopsychiatry 1985;55:190-210.

99. Lahti J, Raikkonen K, Kajantie E, et al. Small body size at birth and behavioral symptoms of AD/HD in children aged five to six years. J Child Psychol Psychiatry 2006;47:1167-74.

100. David OJ, Hoffman SP, Sverd J. Lead and hyperactivity. Behavioral response to chelation: a pilot study. Am J Psychiatry
1976;133:1155-8.

101. Moon C, Marlowe M, Stellern J. Main and interaction effects of metallic pollutants on cognitive functioning. J Learn Disabil 1985;18:217-27.

102. Brucker-Davis F. Effects of environmental synthetic chemicals on thyroid function. Thyroid 1998;8:827-56.

103. Kidd PM. Attention deficit/hyperactivity disorder in children: rationale for its integrative management. Altern Med Rev 2000;5:402-28.

104. Needleman HL, Gunnoe C, Leviton A, et al. Deficits in psychological and classroom performance of children with elevated dentine lead levels. N Engl J Med 1979;300:689-95.

105. Needleman HL, Shell A, Bellinger D, et al. The long-term effects of exposure to low doses of lead in childhood: an 11 year follow-up report. N Engl J Med 1990;311:838.

106. Barkley RA, ADHD: a handbook for diagnosis and treatment. 3rd ed. New York: Guilford Press; 2005.

107. Larsson JO, Larsson H, Lichtenstein P. Genetic and environmental contributions to stability and change of ADHD symptoms between 8 and 13 years of age: a longitudinal twin study. J Am Acad Child Adolesc Psychiatry 2004;43:1267-75.

108. Johnston C, Mash EJ. Families of children with attention-deficit/hyperactivity disorder: review and recommendations for future research. Clin Child Fam Psychol Rev 2001;4:183-207.

109. Sonuga-Barke EJS, Daley D, Thompson $\mathrm{M}$, et al. Parent based therapies for preschool attention deficit/hyperactivity disorder: a randomized controlled trial with a community sample. J Am Acad Child Adolesc Psychiatry 2001;40:402-8.

110. Bor W, Sanders MR, Markie-Dadds C. The effects of the triple p-positive parenting program on preschool children with cooccurring disruptive behavior and attentional/hyperactive difficulties. J Child Psychol Psychiatry 2002;30:571-8.

111. Mash EJ, Johnston C. A comparison of the mother-child interactions of younger and older hyperactive and normal children. Child Dev 1982;53:1371-81.

112. Befera MS, Barkley RA. Hyperactive and normal girls and boys: mother-child interaction, parent psychiatric status and child psychopathology. J Child Psychol Psychiatry 1985;26:439-52.

113. Buhrmester D, Camparo L, Christensen A, et al. Mothers and fathers interacting in dyads and triads with normal and hyperactive sons. Dev Psychol 1992;28:500-9.

114. Gardner FEM. The quality of joint activity between mothers and their children with behaviour problems. J Child Psychol Psychiatry 1994;35:935-48.

115. Johnston C, Mash EJ. Families of children with attention-deficit/hyperactivity disorder: review and recommendations for future research. Clin Child Fam Psychol Rev 2001;4:183-207.

116. Befera MS, Barkley RA. Hyperactive and normal girls and boys: mother-child interaction, parent psychiatric status and child psychopathology. J Child Psychol Psychiatry 1985;26:439-52.

117. Danforth JS, Barkley RA, Stokes TF. Observations of parent-child interactions with hyperactive children: research and clinical implications. Clin Psychol Rev 1991;11:703-27.

118. Gomez R, Sanson AV. Mother-child interactions and noncompliance in hyperactive boys with and without conduct problems. J Child Psychol Psychiatry 1994;35:477-90.

119. Johnston C. Parent characteristics and parent-child interactions in families of non-problem children and ADHD children with higher and lower levels of oppositional-defiant disorder. J Abnorm Child Psychol 1996;24:85-104.

120. Barkley RA. Hyperactive girls and boys: stimulant drug effects on mother-child interactions. J Child Psychol Psychiatry 1989;30:379-90.

121. Befera M, Barkley RA. Hyperactive and normal girls and boys: mother-child interactions, parent psychiatric status, and child psychopathology. J Child Psychol Psychiatry 1984;26:439-52.

122. Edwards F, Barkley R, Laneri M, et al. Parent-adolescent conflict in teenagers with ADHD and ODD. J Abnorm Child Psychol 2001;29:557-72.

123. Biederman J, Faraone SV, Keenan K, et al. Further evidence for family-genetic risk factors in attention-deficit hyperactivity disorder - patterns of comorbidity in probands and relatives in psychiatrically and pediatrically referred samples. Arch Gen Psychiatry 1992;49:728-38.

124. Smalley SL, McGough JJ, Del'Homme M, et al. Familial clustering of symptoms and disruptive behaviors in multiplex families with attention-deficit/hyperactivity disorder. J Am Acad Child Adolesc Psychiatry 2000;39:1135-43.

125. Evans SW, Vallano G, Pelham W. Treatment of parenting behavior with psychostimulant: a case of study of an adult with attention deficit hyperactivity disorder. J Child Adolesc Psychopharmacol 1994;4:63-9.

126. Harvey E, Danforth JS, McKee TE, et al. Parenting of children with attentiondeficit/hyperactivity disorder (ADHD): the role of parental ADHD symptomatol- 
ogy. J Attention Disord 2003;7:31-42.

127. Sonuga-Barke EJS, Daley D, Thompson M. Does maternal $\mathrm{AD} / \mathrm{HD}$ reduce the effectiveness of parent training for preschool children's AD/HD? J Am Acad Child Adolesc Psychiatry 2002;41:696-702.

128. Spencer TJ, Brown A, Seidman LJ, et al. Effect of psychostimulants on brain structure and function in ADHD: a qualitative literature review of magnetic resonance imaging-based neuroimaging studies. J Clin Psychiatry 2013;74:902-17.

129. Jacobvitz D, Sroufe L, Stewart M, Leffert N. Treatment of attentional and hyperactivity problems in children with sympathomimetic drugs: a comprehensive review. J Am Acad Child Adolesc Psychiatry 1990;29:677-88

130. Richters J, Arnold LEA, Jenson PS. NIMH collaborative multimodal treatment study of children with ADHD (MTA): ADHD: I. Background and rationale. J Am Acad Child Adolesc Psychiatry 1995;34:9871000.

131. Boris M, Mandel FS. Foods and additives are common causes of the attention deficit hyperactive disorder in children. Ann Allergy Asthma Immunol 1994;72:462-8.

132. Schnoll R, Burshteyn D, Cea-Aravena J. Nutrition in the treatment of attention deficit hyperactivity disorder; a neglected but important aspect. Appl Psychophysiol Biofeedback 2003;28:63-75.

133. Bateman B, Warner J0, Hutchinson E, et al. The effects of a double blind, placebo controlled, artificial food colourings and benzoate preservative challenge on hyperactivity in a general population sample of preschool children. Arch Dis Childhood 2004;89:506-11.

134. Eigenmann PA, Haenggeli CA. Food colouring and preservatives - allergy and hyperactivity. Lancet 2004;364:823-4.

135 Copeland WE, Angold A, Costello EJ, Egger H. Prevalence, comorbidity, and correlates of DSM-5 proposed disruptive mood dysregulation disorder. Am J Psychiatry 2013;170:173-9.

136. Gillberg C, Gillberg CI, Rasmussen P, et al. Co- existing disorders in ADHD - implications for diagnosis and intervention. Eur J Adolesc Psychiatry 2004;13:180-92.

137. Rappley MD. Clinical practice. Attention deficit-hyperactivity disorder. N Engl J Med 2005;352:165-73.

138 Kadesjo C, Kadesjo B, Hagglof B, Gillberg C. ADHD in Swedish 3- to 7-year-old children. J Am Acad Child Adolesc Psychiatry 2001;40:1021-8.

139. Ford T, Goodman R, Meltzer H. The British Child and Adolescent Mental Health Survey 1999: the prevalence of DSM-IV disorders. J Am Acad Child
Adolesc Psychiatry 2003;42:1203-11.

140. Van Lier PA, Der Ende JV, Koot HM, Verhulst FC. Which better predicts conduct problems? The relationship of trajectories of conduct problems with ODD and ADHD symptoms from childhood into adolescence. J Child Psychol Psychiatry 2007;48:601-8.

141. Larson K, Russ SA, Kahn RS, Halfon N. Patterns of comorbidity, functioning, and service use for US children with ADHD, 2007. Pediatrics 2011;127:462-70.

142. Minde K, Eakin L, Hechtman L, et al. The psychosocial functioning of children and spouses of adults with ADHD. J Child Psychol Psychiatry 2003;44:637-46.

143. Loeber R, Burke JD, Lahey BB, et al. Oppositional defiant and conduct disorder: a review of the past 10 years, part I. J Am Acad Child Adolesc Psychiatry 2000;39:1468-84.

144. Lahey BB, McBurnett K, Loeber R, eds. Are attention-deficit/hyperactivity disorder and oppositional defiant disorder developmental precursors to conduct disorder? In: Handbook of developmental psychopathology. New York: Springer US; 2000. pp. 431-446.

145. Emck C, Bosscher RJ, van Wieringen PC, et al. Psychiatric symptoms in children with gross motor problems. Adapt Phys Activ Q 2012;29:161-78.

146. Fliers E, Rommelse N, Vermeulen SHHM, et al. Motor coordination problems in children and adolescents with adhd rated by parents and teachers: effects of age and gender. J Neural Transm 2008;115:211-20.

147. Gillberg C. Hyperactivity, inattention, and motor control problems: prevalence, comorbidity and background factors. Folia Phoniatr Logop 1998;50:107-17.

148. Mariani MA, Barkley RA. Neuropsychological and academic functioning in preschool boys with attention deficit hyperactivity disorder. Dev Neuropsychol 1997;13:111-29.

149 Kadesjo B, Gillberg C. The comorbidity of ADHD in the general population of Swedish school-age children. J Child Psychol Psychiatry 2001;42:487-92.

150. Geuze RH, Jongmans M, Schoemaker M, Smits-Engelsman B. Developmental coordination disorder. Hum Mov Sci 2001;20:1-5.

151. Wilson PH. practitioner review: approaches to assessment and treatment of children with DCD: an evaluative review. J Child Psychol Psychiatry 2005;46:806-23.

152. Hale JB, Reddy LA, Semrud-Clikeman M, et al. Executive impairment determines ADHD medication response: implications for academic achievement. J Learn Disabil 2011;44:196-212.

153. Daley D, Birchwood J. ADHD and academ- ic performance: why does ADHD impact on academic performance and what can be done to support ADHD children in the classroom?. Child Care Health Dev 2010;36:455-64.

154. Das AK, Gichuru M, Singh A. Implementing inclusive education in Delhi, India: regular school teachers' preferences for professional development delivery modes. Professional Dev Edu 2013 [In press].

155. Lahey BB, Pelham WE, Schaughency EA, et al. Dimensions and types of attention deficit disorder with hyperactivity in children: a factor and cluster-analytic approach. J Am Acad Child Adolesc Psychiatry 1988;27:330-5.

156. Rucklidge JJ, Tannock R. Neuropsychological profiles of adolescents with ADHD: effects of reading difficulties and gender. J Child Psychol Psychiatry 2002;43:988-1003.

157. DuPaul GJ, McGoey KE, Eckert TL, VanBrakle J. Preschool children with attention-deficit/hyperactivity disorder: impairments in behavioural, social and school functioning. J Am Acad Child AdolescPsychiatry 2001;40:508-15.

158. Newborg J, Stock JR, Wnek L, et al. Battelle developmental inventory. Allen: DLM; 1988.

159. Börger N, Meere JVD. Visual behaviour of ADHD children during an attention test: an almost forgotten variable. J Child Psychol Psychiatry 2000;41:525-32.

160. McGee R, Willians S, Feehan M Attention deficit disorder and age of onset of problems behaviors. J Abnorm Child Psychol 1992;20:487-502.

161. Sonuga-Barke EJS, Lamparelli M Stevenson J, et al. Behaviour problems and pre-school intellectual attainment. The associations of hyperactivity and conduct problems. J Child Psychol Psychiatry 1994;35:949-60.

162. Peterson BS, Pine DS, Cohen P, Brook JS. Prospective, longitudinal study of tic, obsessive-compulsive, and attentiondeficit/hyperactivity disorders in an epidemiological sample. J Am Acad Child Adolesc Psychiatry 2001;40:685-95.

163. Cunningham CE, Bremner R, Boyle M Large group community based parenting programs for families of preschoolers at risk for disruptive behaviour disorders: utilization, cost effectiveness, and outcome. J Child Psychol Psychiatry 1995;36:1141-59.

164. Olson S, Brodfeld PL. Assessment of peer rejection and externalizing behaviour problem in preschool boys; a short term longitudinal study. J Abnorm Child Psychol 1991;19:493-503.

165. Pelham WE, Wheeler T, Chronis A 
Empirically supported psychosocial treatments for attention deficit hyperactivity disorder. J Clin Child Psychol 1998;27:190-205.

166. Slomkowski C, Klein RG, Mannuzza S. Is self-esteem an important outcome in hyperactive children? J Abnorm Child Psychol 1995;23:303-15.

167. Lakhan R. Inclusion of children with intellectual and multiple disabilities: a community-based rehabilitation approach, India. J Spec Educ Rehabil 2013;14:79-97.

168. Whalen CK, Henker B, Dotemoto S. Methylphenidate and hyperactivity: Effects on teacher behaviors. Science 1980;208:1280-2.

169. Barkley RA, Fischer M, Edelbrock CS, Smallish L. The adolescent outcome of hyperactive children diagnosed by research criteria: I. An 8-year prospective follow-up study. J Am Acad Child Adolesc Psychiatry 1990;29:546-57.

170. Erhardt D, Hinshaw SP. Initial sociometric impressions of attention-deficit hyperactivity disorder and comparison boys: predictions from social behaviors and from non behavioral variables. J Consult Clin Psychol 1994;62:833-42.

171. Gresham FM, MacMillan DL, Bocian KM, et al. Comorbidity of hyperactivityimpulsivity-inattention and conduct problems: risk factors in social, affective, and academic domains. J Abnorm Child Psychol 1998;26:393-406.

172. Hinshaw SP, Melnick S. M. Peer relationships in boys with attention-deficit hyperactivity disorder with and without comorbid aggression. Dev Psychopathol 1995;7:627-47.

173. Newcorn JH, Miller SR, Ivanova I, et al. Adolescent outcome of ADHD: impact of childhood conduct and anxiety disorder. CNS Spectrums 2004;9:668-78.

174. Kendrick D, Mulvaney CA, Ye L, et al. Parenting interventions for the prevention of unintentional injuries in childhood. 2013. Available from: www.updatesoftware.com/pdf/CD006020.pdf

175. Mitchell EA, Aman MG, Turbott SH, Manku, M. Clinical characteristics and serum essential fatty acid levels in hyperactive children. Clin Pediatr 1987;26:40611.

176. Reebye PN. Diagnosis and treatment of ADHD in preschoolers. Paper presented at the annual meeting of the American Academy of Child and Adolescent Psychiatry, Toronto, October 1997.

177. Jensen PS, Shervette RE, et al. Psychosocial and medical histories of stimulant treated children. J Am Acad Child Adolesc Psychiatry 1988;27:798-801.

178. Rowe R, Maughan B, Goodman R.
Childhood psychiatric disorder and unintentional injury; findings from a national cohort. J Pediatr Psychol 2004;29:119-30.

179. DiScala C, Lescohier I, Barthel M, Li GH. Injuries to children with attention deficit hyperactivity disorder. Pediatrics 1998;102:1415-21.

180. Mori L, Peterson L. Knowledge of safety of high and low active-impulsive boys: implications for child injury prevention. J Clin Child Psychol 1995;24:370-6.

181. Cao Q, Sun L, Gong G, et al. The macrostructural and microstructural abnormalities of corpus callosum in children with attention deficit/hyperactivity disorder: a combined morphometric and diffusion tensor MRI study. Brain Res 2010;1310:172-80.

182. Gruber R, Sadeh A, Raviv A. Instability of sleep patterns in children with attentiondeficit/hyperactivity disorder. J Am Acad Child Adolesc Psychiatry 2000;39:495-501.

183. Corkum P, Moldofsky H, Hogg-Johnson S, et al. Sleep problems in children with attention-deficit/hyperactivity disorder: impact of subtype, comorbidity, and stimulant medication. J Am Acad Child Adolesc Psychiatry 1999;38:1285-93.

184. Lam LT, Yang L. Duration of sleep and ADHD tendency among adolescents in China. J Atten Disord 2008;11:437-44.

185. Lecendreux M, Konofal E, Bouvard M, et al. Sleep and alertness in children with ADHD. J Child Psychol Psychiatry 2000;41:803-12.

186. Daley D, Jones K, Hutchings J, Thompson M. Attention deficit hyperactivity disorder in pre school children: current findings, recommended interventions and future directions. Child Care Health Dev 2009;35:754-66.

187. Gadow K, Nolan E. Differences between preschool children with ODD, ADHD, and ODD \& ADHD symptoms. J Child Psychol Psychiatry 2002;43:191-201.

188. Sonuga-Barke EJS, Dalen L, Remmington B. Do executive deficits and delay aversion make independent contributions to preschool attention-deficit/hyperactivity disorder? J Am Acad Child Adolesc Psychiatry 2003;42:1335-42.

189. Sonuga-Barke EJS, Auerbach J, Campbell $\mathrm{SB}$, et al. Varieties of preschool hyperactivity: multiple pathways from risk to disorder. Dev Sci 2005;8:141-50.

190. Weiss M, Trokenberg-Hechtman L, Weiss G. ADHD in adulthood. A guide to current theory, diagnosis, and treatment. Baltimore: The Johns Hopkins University Press; 1999.

191. Fischer M, Barkley RA, Fletcher KE, Smallish L. The adolescent outcome of hyperactive children - predictors of psychiatric, academic, social, and emotional adjustment. J Am Acad Child Adolesc Psychiatry 1993;32:324-32.

192. Depue BE, Burgess GC, Willcutt EG, et al. Symptom-correlated brain regions in young adults with combined-type ADHD: their organization, variability, and relation to behavioral performance. Psychiatry Res Neuroimag 2010;182:96102.

193. Biederman J, Faraone SV, Knee D, Munir K. Retrospective assessment of DSM-III attention deficit disorder in non-referred individuals. J Clin Psychiatry 1990;51: 102-6.

194. Dinn WM, Robbins NC, Harris CL. Adult attention-deficit/hyperactivity disorder: neuropsychological correlates and clinical presentation. Brain Cogn 2001;46:114-21.

195. Muglia P, Jain U, Macciardi F, Kennedy JL. Adult attention deficit hyperactivity disorder and the dopamine D4 receptor gene. Am J Med Genet 2000;96:273-7.

196. Hesslinger B, Thiel T, Van Elst LT, et al. Attention-deficit disorder in adults with or without hyperactivity: where is the difference? A study in humans using short echo H-1-magnetic resonance spectroscopy. Neurosci Lett 2001;304:117-9.

197. Sachdev P. Attention deficit hyperactivity disorder in adults. Psychol Med 1999;29:507-14.

198. Widiger TA, Clark LA. Toward DSM-V and the classification of psychopathology. Psychol Bull 2000;126:946.

199. Szasz T. Pharmacracy: medicine and politics in America. Westport: Praeger; 2003.

200. Mahone EM. Not too basic, not too technical: a new ADHD resource. Clin Neuropsychol 2001;26:700-3.

201. Laungani P. Mindless psychiatry and dubious ethics. Couns Psychol Q 2002;15:23-33.

202. Taylor M, O’Donoghue T, Houghton S. To medicate or not to medicate? The decision-making process of western australian parents following their child's diagnosis with an attention deficit hyperactivity disorder. Int J Disabil Develop Educ 2006;53:111-28.

203. Furman L. What is attention-deficit hyperactivity disorder (ADHD)? J Child Neurol 2005;20:994-1002.

204. Hart H, Chantiluke K, Cubillo AI, et al. Pattern classification of response inhibition in ADHD: Toward the development of neurobiological markers for ADHD. Hum Brain Mapp 2014;35:3083-94.

205. Bochner AP. Terms of perfection. Rev Commun 2012;12:3-20.

206. Shaw P, Gormick M, Lerch J. Polymorphisms of the dopamine D4 receptor, clinical outcome, and cortical structure in attention-deficit/hyperactivity disorder. Arch Gen Psychiatry 
2007;64:921-31.

207. Lasky-Su J, Biederman J, Laired N. Evidence for an association of the dopamine D5 receptor gene on age at onset of attention deficit hyperactivity disorder. Ann Hum Genet 2007; 1:648-59.

208. Linnet KM, Dalsgard S, Obel C, et al. Maternal lifestyle factor in pregnancy risk of attention deficit hyperactivity disorder and associated behaviors: review of the current evidence. Am J Psychiatry 2003;60;1028-40.

209. Barkely RA, Fisher M, Smallish L, Fletcher K. Young adult follow-up of hyperactive children: antesocial activities and drug use. J Child Psychol Psychiatry 2004;45:195-211.

210. Haberstick BC, Timberlake D, Hopfer CJ, et al. Genetic and environmental contributions to retrospectively reported DSMIV childhood attention defict hyperactivity disorder. Psychol Med 2008;38:1057-66.

211. Race S. Change your diet and change your life: food intolerance and food allergy handbook. Northumberland: Tigmor Books; 2012.

212. Prinz RJ, Roberts WA, Hantman E. Dietry correlates of hyperactive behavior in children. J Consult Psychol 1980;48:760-9.

213. Vance ALA, Luk ESL. Attention deficit hyperactivity disorder: current progress and controversies. Aust N Z J Psychiatry 2000;34:719-30.

214. Normand S, Flora DB, Toplak ME, Tannock R. Evidence for a general ADHD factor from a longitudinal general school population study. J Abnorm Child Psychol 2012;40:555-57.

215. Ashley S. 1000 best tips for ADHD: expert answers and bright advice to help you and your child. Chicago; Sourcebooks, Inc.: 2012.

216. Fisher BC. Attention deficit disorder misdiagnosis. Boca Ration: CRC Press; 1998.

217. Visser J. Developmental coordination disorder: a review of research on subtypes and comorbidities. Hum Mov Sci 2003;22:479-93.

218. Habel LA, Cooper WO, Sox CM, et al. ADHD medications and risk of serious cardiovascular events in young and middle-aged adults. JAMA 2011;306:2673-83.

219. [No authors listed]. A14-month randomized clinical trial of treatment strategies for Attention-deficit hyperactivity disorder. Arch Gen Psychiatry 1999;56:107386.p

220. Singh A. Parent completed developmental screening: validity and reliability of the 6 years ages and stages questionnaire interval. Doctoral Dissertation, University of Oregon.

221. Singh A, Squires J. ADHD in preschool: approaches and teacher training. $\mathrm{J}$ Am Acad Special Educ 2014;3:122-49.

222. Lakhan R, Singh A. Early intervention tool (EIT) for children with developmental delay in India: a pilot study. Eur Health Psychol 2014;16:18-25.

223. Verma N, Singh A. Stress management \& coping embedded in the Bhagwad Gita. Ind J Health Wellbeing 2014;5:517-9.

224. Yeh CJ, Singh A. Promote creative instruction and mathematics thinking for young children, tenth annual bill martin jr memorial symposium, 2014, Texas A\&M University Commerce.

225. Singh A, Yeh CJ, Das A, et al. Develop research-based early childhood science curriculum model for diverse students. 2014. 25th International Conference organized by the Society for Information Technology \& Teacher Education, Jacksonville, Florida.

226. Singh A. Psycho techniques and behavior modification techniques in organizational management. 2006. Organized by the Rehabilitation Council of India \& Educatum.

227. Singh A, Prem G, Sai 0. mood disorder with mental retardation. 1996. Organized by the National Institute for the Mentally Handicapped, India.

228. Elia J, Ambrosini PJ, Rapoport JL. Treatment of attention-deficit-hyperactivity disorder. N Engl J Med 1999;340:780-8.

229. Das A, Singh A. Training needs of secondary regular education teachers to implement inclusive education in Delhi, India. In: Society for Information Technology \& Teacher Education International Conference, 2013. pp 5003-5003. 